\title{
Approaching Al and Robotics in an Eco-friendly Way
}

\section{Pagliarini, Luigi; Lund, Henrik Hautop}

Published in:

Journal of Robotics Networks and Artificial Life

Link to article, DOI:

10.2991/jrnal.k.200222.002

Publication date:

2020

Document Version

Publisher's PDF, also known as Version of record

Link back to DTU Orbit

Citation (APA):

Pagliarini, L., \& Lund, H. H. (2020). Approaching Al and Robotics in an Eco-friendly Way. Journal of Robotics Networks and Artificial Life, 6(4), 217 - 220. https://doi.org/10.2991/jrnal.k.200222.002

\section{General rights}

Copyright and moral rights for the publications made accessible in the public portal are retained by the authors and/or other copyright owners and it is a condition of accessing publications that users recognise and abide by the legal requirements associated with these rights.

- Users may download and print one copy of any publication from the public portal for the purpose of private study or research.

- You may not further distribute the material or use it for any profit-making activity or commercial gain

- You may freely distribute the URL identifying the publication in the public portal

If you believe that this document breaches copyright please contact us providing details, and we will remove access to the work immediately and investigate your claim 
Research Article

\title{
Approaching Al and Robotics in an Eco-friendly Way
}

\author{
Luigi Pagliarini ${ }^{1,2,3, *}$, Henrik Hautop Lund ${ }^{1}$ \\ ${ }^{1}$ Centre for Playware, Technical University of Denmark, 2800 Kgs. Lyngby, Denmark \\ ${ }^{2}$ Academy of Fine Arts of Macerata, Via Berardi, 6, Macerata 405111, Italy \\ ${ }^{3}$ ISIA Design, Via C. Battisti, 198, Pescara 65123, Italy
}

\begin{abstract}
ARTICLE INFO
Article History

Received 27 November 2019

Accepted 14 December 2019

Keywords

Eco-technology

Playware

user-friendly robotics

artificial intelligence

sustainable technologies

eco-friendly high-tech
\end{abstract}

\begin{abstract}
Merging among them the most important open questions of the century, in this paper, we outline and define a wide range of possible applications and technical forms of a low-energy dissipation in robotic biotechnological system conceived for intelligent and playful interactions. Moving from earlier works on Wearable and Modular Robotics, we describe how, by using modular robotics for creating wearable, it is possible to obtain an approximatively self-sustainable and flexible wearable system, consisting of freely inter-changeable input/output modules that through the use of solar, mechanical, and other sources of renewable energy are able to suit some specific tasks. Therefore, we here attempt to drive the attention on early prototypes to show the potentialities of such an approach, and focus on depicting possible application in the future of high-tech domain. Indeed, our artistic experiment is a clear example of how to scale down electronics to an eco-sustainable paradigm, which can still create playful and useful interactions for many application domains.
\end{abstract}

(C) 2020 The Authors. Published by Atlantis Press SARL.

This is an open access article distributed under the CC BY-NC 4.0 license (http://creativecommons.org/licenses/by-nc/4.0/).

\section{INTRODUCTION}

Robotics, Artificial Intelligence (AI), and environmental sustainability are the main trends of our own century. Therefore, the inevitable destiny of all of the future high-tech products is to align to the process of reducing the environmental impact both in terms of production process, materials, and consumption. For this reason, electronics, computing, and robotics too should try to reduce their environmental effect from the design phase. To work on design choices to improve sustainability, designers need clear information on how to keep the whole process untroublesome, sustainable and doable. As a consequence, such product design consists both of choosing between an enormous array of options and, vice versa, a very limited subset of potentials.

Therefore, the main intention of the PixelBeing Project, presented here, is to design an artifact able to provide product designers with useful insights into the main triggers of environmental impacts, so they can change their design conception to be more environmentally friendly. We do so either to support eco-design strategies and to create necessarily low-cost and eco-friendly products, while keeping in mind that any product still needs to spare its basic characteristics as robustness, flexibility and easiness in user-support provided by any developer. Our goal was to realize a prototype that, in part, is a tool for product designers with which they are able to quickly see, compare and assess design variations without needing to go through the whole experimental process, building on the playware research methodology [1]. Indeed, eco-friendly design factors, such as mass, energy use and transport volume, etc. are very

"Corresponding author.Email: luigipagliarini@gmail.com many and difficult to ensemble together in the same production, and our experimentation shapes some knowledges that might provide easy entry points to make design improvements and allows designers to develop product-specific guidelines.

We consider our research piece as part of future investigation that must face a concrete challenge, a challenge that might lead towards an epochal change while, on the other hand, the PixelBeing project being a handmade art-oriented research piece (building on previous robot art investigations [2]) carries along with it a relatively low-demanding output in terms of tangible industrial production, by now, and on the opposite an extra request to fulfill a serious request in terms of innovative aesthetical results.

The PixelBeing philosophy was intended to revisit both the process and the product of AI and Robotics artifacts under a more ethical light. We kind of opened a new research process looking for the best ways to analyze hotspots and opportunities in the production life cycles under an economical point of view, without sacrificing efficient, accurate and transparent results. We did that in many ways. A first example regards materials. In PixelBeing it has been a search on the most available and accessible, easy and effortless production methods that avoid the use of plastic or other toxic and high-impact materials as much as possible. Another clear example are methods. In PixelBeing we tried to minimize either the size and the value or the implant difficulty, in terms of speed and effort, of any given functional component, as well as, we focused on technologies where the lifespan of the whole structure and replacement of broken parts is an essential target. One last example regards energy. We are focusing our research efforts on the most obvious energy impact of the technology in use. In PixelBeing, indeed, we mostly make use of solar panel circuits and we are actually immerged in 
the process of implementing mechanical energy ones in the form of kinetic energy, in which objects have the ability to do work when they move, and potential energy, in which objects have the ability to do work due to its own position.

In short, this electronic art project aims at an initial renovation of the idea of robotics so that it will be able, in the near future, to reach the design, production and consumption of objects that are ethically more adequate in the sense of eco-sustainability.

\section{THE PIXELBEING PROJECT}

PixelBeing is a project for a theatrical character that consists of a robotic system to be worn on the body (derived from previous work $[3,4])$. It is meant to produce aesthetical and playful interactions, and it is built using concepts derived from modular robotics and modular Playware $[5,6]$. It foresees a full body suit made of a mask, gloves, shoes and a flexible wearable processing system, where freely interchangeable input/output modules can be positioned on the body suit in accordance with the aesthetical demand and tasks, at hand. The idea is to implement both a virtual (sensors-based) interaction and a more physical one to reach a wider range of possible outcomes, behaviorally and aesthetically. Therefore, the basic challenge is to design a general interface that focuses on the users' body interaction with the real world, and possibly with a social environment. At the currents state we have tested the general principles and have developed the mask as well as started assembling the gloves and the body costume.

This project mainly focuses on eco-friendly technologies and processes and tries to exploit the sustainability of any electronic (art) tools. It makes use of recycled components, biomaterials and supports, solar panels and all of the possible sources of renewable energies, and it also pay attention to the principle that procedures and resources should be as natural and easy to access, as much as possible.

The basic idea is a suit that ends up to be the playfield where to arrange different mechanical, electronic and electromechanical modules according to any need. The modules we use on it can be either isolated or interconnected and should be made so that they can be easily and quickly relocated, therefore, the way the resulting

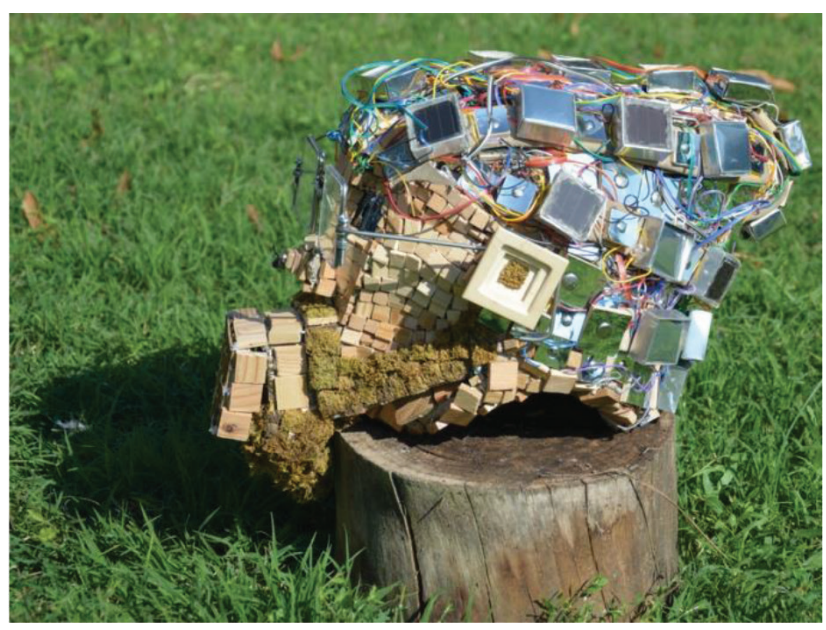

Figure $1 \mid$ PixelBeing bio-technological mask. Lateral view. suit configuration will perform a task will depend both on the modules' specific functionalities and on their physical (or their geographical) displacement on the suit itself. Modularity is essential, and that is because besides of offering a larger variety of possible configurations and activities it is a pretty eco-friendly approach since it allows the less expensive procedure when a subpart of the artifact gets out of work. Of course, such What \& Where System can be applied to a wide and complex number of situations and tested on many potentials and can be used to create body interactions in several application domains.

Therefore, it becomes crucial to experiment the possible "definition" and implementation of the idea of module and of module's functionality. We framed a number of modules general characteristics as: (A) Each module-circuit is fully autonomous energetically and electronically, although a circuit can be thought as 'eventually' connected physically or virtually to others modules, to a font of energy, or to any other computer interface; (B) although there can be exceptions, each single circuit is conceived independently from its final location; (C) a module should be applicable to any geolocation and should be thought as for a general purpose, not limited to any single and specific application.

As said above, modules can be thought as either isolated or interconnected, and in the latter case we think to a communication paradigm where modules can communicate: (A) Locally: Neighbor-to-Neighbor communication (wired or wireless); (B) globally: From one module to a module far away (wireless); (C) one to one communication system; (D) one to many communication systems; (E) Many to many communication systems. Our research, at the moment, can be considered primitive. We aim to evolve it in many different ways and a grant and/or a team experienced in electronics, robotics, informatics and AI would be ideal to such a goal. Indeed, we wish to implement modules that have a highly significant input set (a large number of sensors, including biofeedback and neurofeedback ones), a clever input pre/processing, and a large set of articulated outputs (including motor actions).

There are few more levels of research embodied into the PixelBeing. The first one explores the use renewable energies. We already furnished PixelBeing with accumulators modules as well as displaced on his head different solar panels modules.

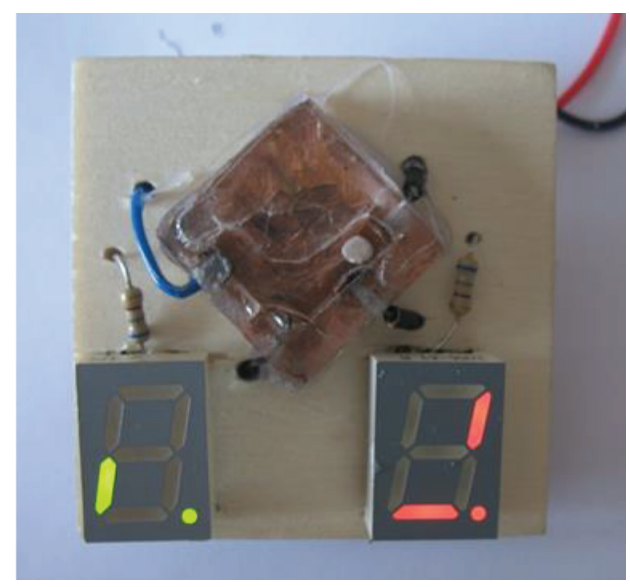

Figure 2 A wooden based PixelBeing's module. First prototype, circuit with switch, sensor and led-based actuators. 


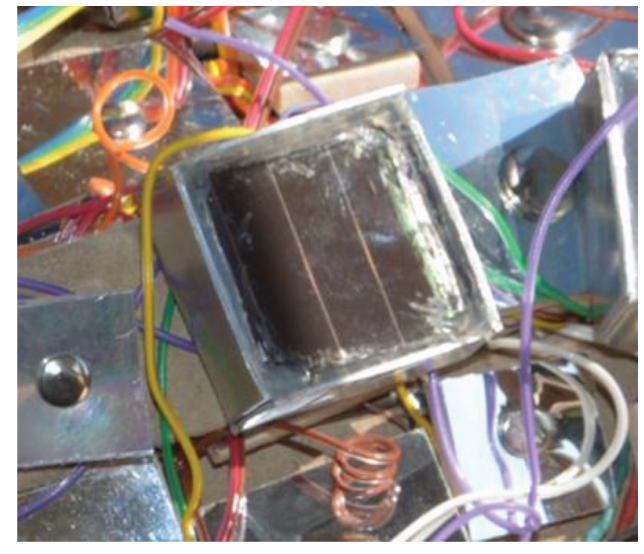

Figure 3 Detail of the PixelBeing mask. A solar-panel-based circuit module mounted on PixelBeing's helmet.

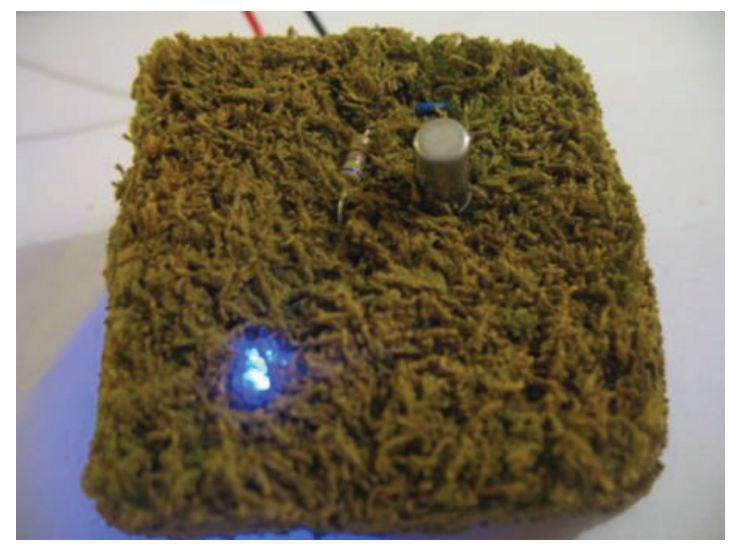

Figure $4 \mid$ A detail of a sense-and-actuate module to be mounted on PixelBeing' suit. Later prototype. A biomaterial-based circuit made out of natural wood and moss.

The two interconnected modules are able to sustain wee electronic circuits and if perfected should be able in the early future to supply enough power to larger circuits.

We are now in the process of exploiting the use of mechanical energy modules of two different kinds. The first one, active, that makes use of the kinetic energy produced by the body of the actor wearing the suit, and the second one, passive, which simply uses the ability of taking advantage to work thanks to gravitational due to its own position in three-dimensional space.

The second level of investigation is digging in the potentialities of the use of biomaterials when building and assembling modules. We are making a real effort trying to integrate electronic circuits within the most natural material. Of course, there are many elementary problems, especially related to the moisture potential, we are slowly overcoming.

Meanwhile we basically aim at reaching such a level of integration where electronics co-exists with alive materials and, probably a dream, circuits are somehow partially fed by the growth such processes like the chlorophyll photosynthesis produced by any plant.

A third level of investigation is the one that focuses on targeting the minimal size of the modules since, often, the smaller modules are the lesser they consume, the more adaptable is to implement the whole structure, and the cheaper to repair/replace broken units.
The fourth level of investigation regards the energy flow. Since the PixelBeing design is a design that fully relies on renewable energies it has to rethink the flow of energy in terms of appropriate modules location. The "electronics space" must be thought in profitable geometrical terms, so that acquiring and distributing energy itself has to be done in most convenient way.

\section{DISCUSSION AND CONCLUSION}

In this paper tried to focus on high-tech future in terms of ecosustainability and described as well as defined a full range of possible implications and the technical contours for a modern robotic biotechnological system. We first depicted the general principles of the new eco-friendly design and later we described how, by using modular robotics for creating wearable, it is possible to approach a self-sustainable and flexible wearable system. Therefore, we built our freely inter-changeable input/output modules system that through the use of renewable energy is able to reach some important goals as well as targets, as for example introduce natural materials and renewable energy in such delicate field as wearable robotics design. We also highlighted four possible basic principles of building eco-friendly artifacts: (A) The use renewable energies; (B) use of biomaterials; (C) minimization of the hardware structures; (D) minimization of energy flow in space. We here described the progresses of our first prototypes to show the potentialities of such an approach, and focus on showing possible future applications in all of the electronics domains. Indeed, our artistic experiment is a clear example of how to scale down electronics to an eco-sustainable level, which can still create functional, playful and useful interactions for many applicative fields.

\section{CONFLICTS OF INTEREST}

The authors declare they have no conflicts of interest.

\section{ACKNOWLEDGMENT}

The authors wish to thank Demian Battisti for the help in developing the first prototype system.

\section{REFERENCES}

[1] H.H. Lund, Playware research - methodological considerations, J. Robot. Netw. Artif. Life 1 (2014), 23-27.

[2] L. Pagliarini, H.H. Lund, The development of robot art, 13th International Symposium on Artificial Life and Robotics, Oita, Japan, 2008, pp. 401-405.

[3] H.H. Lund, L. Pagliarini, Robotic art for wearable, Proceedings of EUROSIAM: European Conference for the Applied Mathematics and Informatics, 2010, p. 10.

[4] L. Pagliarini, H.H. Lund, Wearing the playware, Artif. Life Robot. 15 (2010), 381-384.

[5] H.H. Lund, P. Marti, Designing modular robotic playware, RO-MAN 2009 - The 18th IEEE International Symposium on Robot and Human Interactive Communication, IEEE, Toyama, Japan, 2009, pp. 115-121.

[6] H.H. Lund, Playware ABC: engineering play for everybody, J. Robot. Netw. Artif. Life 3 (2017), 283-286. 


\section{AUTHORS INTRODUCTION}

\section{Prof. Luigi Pagliarini}

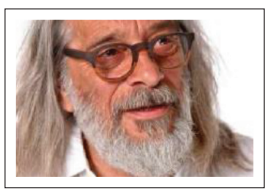

He received his Bachelor's degree in Experimental Psychology at University of St Andrews in 1989 and Master's degree at Università degli Studi di Roma 'La Sapienza' in 1991 and Doctor's degree in Psychology at University of Pavia in 2000 in Italy. He is a neuropsychologist by training, an artist engaged since the early 90 s in Software Art, Robot Art and AI-based Art. At the moment, he is Professor of Theory of Perception and Psychology of Form, Semantics of Bodies at the Academy of Fine Arts in Macerata, and Innovation Design at the ISIA Design Institute of Pescara. He is a Consultant Professor at the Playware of the Danish Technical University where he deals with Robots and Dynamic Agents Interfaces Design. He is also currently a Partner Consultant for Entertainment Robotics. In the past, he has collaborated on various projects with companies such as the LEGO.

\section{Prof. Henrik Hautop Lund}

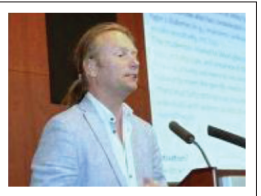

$\mathrm{He}$ is a Professor of Department of Electrical Engineering at Technical University of Denmark. He is head of the Center for Playware, Technical University of Denmark, is World Champion in RoboCup Humanoids Freestyle 2002, and has more than 200 scientific publications and 5000 citations. He was awarded the Most Outstanding Healthcare Innovator in the World in 2019. Over the last year, he received international awards in Tokyo, Singapore, and London. He has developed shape-shifting modular robots, presented to the emperor of Japan, and has collaborated closely on robotics and AI with companies like LEGO, Kompan, BandaiNamco, Microsoft, Mizuno. He is the inventor of the Moto Tiles (www.moto-tiles.com), which are used by seniors all around the world. 